\title{
Toby Hartnell, Ali Asadi. An archaeological survey of water management in the hinterland of Persepolis
}

\section{Sébastien Gondet}

\section{(2) OpenEdition}

1 Journals

\section{Édition électronique}

URL : http://journals.openedition.org/abstractairanica/40510

DOI : 10.4000/abstractairanica.40510

ISSN : 1961-960X

Éditeur :

CNRS (UMR 7528 Mondes iraniens et indiens), Éditions de l'IFRI

\section{Édition imprimée}

Date de publication : 1 décembre 2013

ISSN : 0240-8910

\section{Référence électronique}

Sébastien Gondet, « Toby Hartnell, Ali Asadi. An archaeological survey of water management in the hinterland of Persepolis ", Abstracta Iranica [En ligne], Volume 32-33 | 2013, document 168, mis en ligne le 01 juillet 2016, consulté le 03 octobre 2020. URL : http://journals.openedition.org/ abstractairanica/40510; DOI : https://doi.org/10.4000/abstractairanica.40510

Ce document a été généré automatiquement le 3 octobre 2020.

Tous droits réservés 


\title{
Toby Hartnell, Ali Asadi. An archaeological survey of water management in the hinterland of Persepolis
}

\author{
Sébastien Gondet
}

\section{RÉFÉRENCE}

Toby Hartnell, Ali Asadi. « An archaeological survey of water management in the hinterland of Persepolis », in : P. Matthiae, F. Pinnock, L. Nigro, N. Marchetti, eds., Proceedings of the 6th International Congress of the Archaeology of the Ancient Near East, 5 May-10 May 2009 « Sapienza » - Università di Roma. Vol. 2, Wiesbaden, Harrassowitz, 2010, p. 219-232.

1 Ces deux articles résument les résultats de prospections dans la plaine de Persépolis visant à mieux comprendre l'évolution de l'exploitation de la région à partir de la période achéménide jusqu'au début de l'ère islamique. Ces travaux se situent dans la continuité des ceux de W. Sumner et de son équipe dans les années 1960-70. Deux secteurs ont été prospectés au nord de Persépolis et un autre au sud. Les sites achéménides sont très rares, sauf le long de la rivière Pulvar, où près de 50 sites présenteraient des indices d'occupation de cette période. Ce résultat est à mettre en relation avec les récentes découvertes effectuées le long du Pulvar, plus en amont dans la vallée du Tang-e Bulaghi (Abs. Ir. 29, c.r. $\mathrm{n}^{\circ} 36$ et 67 et ici $\mathrm{n}^{\circ}$ 38). La vallée du Pulvar, qui reliait les deux sites royaux de Pasargades et Persépolis, aurait été occupée à l'achéménide par de petites installations rurales. Dans les deux autres secteurs, les sites sont en majorité sassanides et islamiques. Si au nord-ouest de la plaine, des indices d'occupation pré-achéménide ont été relevés, au sud l'exploitation du territoire se développe seulement entre l'époque sassanide et les débuts de l'ère islamique. D'après les AA., le modèle d'occupation de la plaine aurait évolué entre l'achéménide, où les 
sites sont sur les pentes des reliefs, vers une installation dans la plaine à l'époque sassanide, permise par l'existence de vastes réseaux d'irrigation et marquée par de nombreux sites hiérarchisés. Cette hypothèse de restitution ne tient pas compte des réseaux de canaux de l'époque achéménide, alimentés par le Kur, l'autre rivière qui arrose la plaine. Leur existence tend à prouver que la plaine, au moins dans sa partie nord, était exploitée à l'époque achéménide, mais il est possible que les preuves de cette exploitation aient en grande partie disparu du fait des graves transformations récentes du paysage.

2 [Ce texte concerne également le $\mathbf{n}^{\circ} 169$ ]

\section{AUTEURS}

SÉBASTIEN GONDET

Université Lyon 2 